BULLETIN Bulletin hispanique

HISPANIQUE Université Michel de Montaigne Bordeaux

119-2 | 2017

La Égloga renacentista en el Reino de Nápoles

\title{
La Égloga Nice de Juan de la Vega
}

\section{Maria D'Agostino}

\section{(2) OpenEdition}

\section{Journals}

Edición electrónica

URL: http://journals.openedition.org/bulletinhispanique/5154

DOI: 10.4000/bulletinhispanique.5154

ISSN: $1775-3821$

\section{Editor}

Presses universitaires de Bordeaux

\section{Edición impresa}

Fecha de publicación: 1 diciembre 2017

Paginación: 639-672

ISBN: 979-10-300-0218-8

ISSN: 0007-4640

\section{Referencia electrónica}

Maria D'Agostino, «La Égloga Nice de Juan de la Vega», Bulletin hispanique [En línea], 119-2 | 2017, Publicado el 28 diciembre 2020, consultado el 15 enero 2021. URL: http://journals.openedition.org/ bulletinhispanique/5154 ; DOI: https://doi.org/10.4000/bulletinhispanique.5154 


\title{
La Égloga Nice de Juan de la Vega
}

\author{
Maria D'Agostino \\ Università degli Studi Suor Orsola Benincasa
}

L’article présente la Égloga Nice, inédite, de Juan de la Vega, auteur méconnu des Versos de Juan de la Vega (Naples, Mattia Cancer, 1552), tout aussi méconnus. Le texte présente des points d'intérêt, tant du point de vue de la forme - sa structure polymétrique - que du contenu : il s'agit d'un éloge politique, dans les années 15471552, cruciales pour l'équilibre délicat de la vice-royauté. L'article propose une série d'hypothèses relatives à la représentation diversifiée de la majesté de don Pedro de Tolède et de son entourage, de l'aube au crépuscule de son gouvernement.

Mots-clés: Juan de la Vega, Égloga Nice, Juana de Aragón, Vittoria Colonna de Aragón.

El artículo presenta la inédita Égloga Nice de Juan de la Vega, autor desconocido de los también desconocidos Versos de Juan de la Vega (Nápoles, Mattia Cancer, 1552). El texto ofrece numerosos motivos de interés, tanto desde el punto de vista formal -la articulada estructura polimétrica-, cuanto desde el de los contenidos : su valor encomiástico y político en los años 1547 a 1552, cruciales para el delicado equilibrio del reino. Propone una serie de hipótesis relativas a la diversa representación de la majestad de don Pedro de Toledo y de su entorno entre el amanecer y el ocaso de su gobierno.

Palabras clave: Juan de la Vega, Égloga Nice, Juana de Aragón, Vittoria Colonna de Aragón.

This article analyses the unpublished 'Egloga Nice', by Juan de la Vega, the still obscure poet of the still unknown and unpublished 'Versos de Juan de la Vega' (Napoli, Mattia Cancer, 1552). The Egloga presents several interesting aspects with regard to its structure -for instance the text multiple uses of poetic metre- as well as its content, especially for the political and encomiastic value -in crucial years for the Vice Kingdom-. The Égloga thus enables us to put forward a series of hypothesis concerning the different representations of the "Majesty" of don Pedro de Toledo and of his entourage from the dawn to the twilight of his government.

Keywords: Juan de la Vega, Égloga Nice, Juana de Aragón, Vittoria Colonna de Aragón. 
Philippus [...] liberalitatiac munificentieprincipum maxime consonum estobsequiorum a viris benemeritis prestitorum minime oblivisci immo ea debitare muneratione prossequi ut et illa premii condigna consequantur et [...] ut considerantes promptum semper atque indefessum animum studium ac fidem necnon obsequia in ministerium nostrum per triginta et novem annorum spatium prestita a fideli nobis dilecto Joanne de Vega in variis bellorum expeditionibus ac presertim in senensi bello ubi intrepidi eius animi plurima vulnera corpori suo inflicta evidens testimonium prebent [...] merito quidem in aliquam prefatorum obsequiorum compensationem pensionem annuam trecentorum ducatorum in prefato nostro citerioris Sicilie Regno illi solvendorum donare censuimus [...] eidem Ioanni de Vega annuos ducatos tercentum usualis monete prefati nostri citerioris Sicilii Regni [...] vita sua perdurante ac dum de nostra mera et libera voluntate processerit seu de equivalenti recompensa $[\ldots]{ }^{1}$

Todavía no he tenido la suerte -y puede que no la tenga nunca- de averiguar a ciencia cierta si el Juan de la Vega mencionado en el largo privilegio del que se acaba de citar el incipit -y al que Felipe II otorga en 1582 un vitalicio de trescientos ducados en su «citeriore Siciliae Regno»- es el mismo Juan de la Vega al que también se le había concedido en 1563 una "merced por una vez» ${ }^{2}$ de la misma cifra -siempre en el Reino de Nápoles-, y si, a su vez, los dos son el mismo Juan de la Vega autor de los Versos que vieron la luz en la capital partenopea en 1552. Creo que sí. Y si todavía no hay prueba de ello, sí hay bastantes indicios para avanzar alguna hipótesis sobre el recorrido vital de este misterioso personaje.

En efecto, como se apuntaba en otra circunstancia ${ }^{3}$, el mismo autor de los Versos nos proporciona en sus textos una serie de noticias que permiten dibujar su perfil.

De hecho, es cierto que Juan de la Vega estaba integrado en el ambiente de la corte virreinal y que tuvo una relación especialmente significativa con Lope de Mardones, influyente mayordomo de don Pedro de Toledo a partir de 1546. Nuestro poeta se dirige a Mardones como a su mecenas el cual: "con mil sus beneficios cotidianos / es firme amparo a mis tribulaciones» [G IIv]. De sus composiciones es posible inferir que el poeta era originario de la región del Tajo, como se lee en algunos versos de la Égloga Nice, en los que se lamenta de la Fortuna (vv. 52-54):

$$
\begin{aligned}
& \text { Que me ha del patrio Tajo desterrado, } \\
& \text { y por estrańas partes me ha traído } \\
& \text {-renovando en mi exemplos muy dolientes- [...] }
\end{aligned}
$$

1. Archivo General de Simancas, Secretarías Provinciales, Lib. 141, f. 142v. El privilegio ocupa los ff. 142v-145v; para la lectura integral del mismo cf. Versos de Juan de la Vega, edición crítica de Maria D’Agostino, Pisa, ETS, de próxima publicación.

2. Para el texto de esta merced véase Maria D’Agostino, “'Lalma de un gran valor ardiente en zelo". Don Pedro de Toledo nella poesia di Juan de la Vega», en Encarnación Sánchez García (ed.), Rinascimento Meridionale. Napoli e il viceré Pedro de Toledo (1532-1553), Napoli, Pironti, 2016, p. 426.

3. Maria D’Agostino y Antonio Gargano, «Cancioneros plurilingües en el Nápoles español. Versos de Juan de la Vega (Mattia Cancer, 1552)», Revista de Poética Medieval, no 28, 2014, pp. 192-193. 
Según lo que relata a Francisco de Medina en una epístola en tercetos, fue soldado, probablemente con el grado de capitán, y puede que oficial de la administración de justicia en una audiencia de provincias 4 .

De los textos se deduce también que tuvo relaciones especialmente significativas, además de con el mismo virrey, destinatario de muchas composiciones y del conjunto de la colección de versos, con las familias de Ávalos y Colonna, en especial con Juana de Aragón y su hija Vittoria, a la cual, después de don Pedro, Juan de la Vega dedica el mayor número de composiciones.

Lo que ahora se quiere poner de relieve es que si se juntan las noticias que proporcionan sus poemas con los datos que transmiten los documentos que hemos encontrado hasta ahora, se tienen suficientes indicios para avanzar una hipótesis: el soldado llegado a Nápoles en tiempos de Carlos V, probablemente en 1541, según el documento citado al comienzo, y que, entre otras, participó en la batalla de Siena -en donde murió el mismo don Pedro de Toledo- dando pruebas de una heroica actitud - «in senensi bello ubi intrepidi eius animi plurima vulnera corpori suo inflictar-, este soldado, decíamos, y el autor de los Versos de Juan de la Vega, son la misma persona.

Los Versos de Juan de la Vega vieron la luz en Nápoles en 1552, publicados por el editor Mattia Cancer. El único ejemplar conocido del impreso se encuentra hoy en día en el Fondo Cuomo de la Biblioteca de la Società Napoletana di Storia Patria con signatura SL.X.H.20(2) .

El volumen es en $8^{\circ}$ y está formado por 11 cuadernillos, con un total de 84 fols. impresos en cursiva; la numeración en mayúsculas y números romanos. En el fol. L3v, el colofón reza: «Impressos en Napoles por Mathio Cancer / el año de nuestra Salud / M. D. LII", mientras en el fol. L4 recto y verso aparece una lista de los «Errores de la stampa de alguna importancia». El frontispicio, más que sobrio, contiene, además del título del volumen, la indicación de que el libro se imprimió «con privilegio real».

Está encuadernado en piel junto con el prosímetro de Paolo Regio, Siracusa piscatoria, publicado en Nápoles por Giovanni de Boy en 1569 y en cuya portada aparece el sello del «Liceo Ginnasiale Principe Umberto di Napoli», indicación del antiguo dueño del ejemplar.

4. Para la posible identificación de Francisco de Medina véase ibid., n. 9.

5. Es cierto que un ejemplar del volumen figuraba en la biblioteca personal del virrey, como se deduce por el Inventario de los bienes del marqués de Villafranca, conservado en el Archivo Histórico Nacional, secc. Osuna, leg. 425, n. 3, fols. 35-41, para el que puede consultarse Carlos José Hernando Sánchez, «Poder y cultura en el Renacimiento napolitano: La Biblioteca del virrey Pedro de Toledo", en Cuadernos de historia moderna, vol. 9, 1988, pp. 13-34; Carlos José Hernando Sánchez, Castilla y Nápoles en el siglo XVI. El virrey Pedro de Toledo. Linaje, estado y cultura (1532-1553), Salamanca, Junta de Castilla y León, Consejería de Cultura y Turismo, 1994, pp. 476-483; Roland Béhar, "Or libro italiano, ora spagnolo...: algunas notas sobre el análisis de la biblioteca de don Pedro», en Encarnación Sánchez García (ed.), Rinascimento Meridionale. Napoli e il viceré Pedro de Toledo (1532-1553), op. cit., pp. 357-370. 
Ambos impresos se presentan en perfecto estado de conservación. En el lomo de la cubierta se lee «Regio Paolo» y debajo Siracusa. El hecho de que en el exterior del volumen no haya rastro de que contiene también los Versos de Juan de la Vega y que la encuadernación que une los dos impresos sea tan cuidada que no permite ver con facilidad dónde acaba el primero y dónde empieza el segundo es probablemente la razón por la que no se ha tenido noticia de los Versos de Juan de la Vega hasta mediados de los años ochenta del siglo pasado ${ }^{6}$.

En efecto, los Versos de Juan de la Vega, como el poeta que los escribió, han quedado en el olvido durante casi cinco siglos. El impreso de 1552 ni siquiera figura en el volumen que Pietro Manzi dedicó a los Annali di Mattia Cancer ed eredi, publicado en el ámbito de los siete volúmenes sobre La tipografia napoletana nel '500, así como tampoco lo mencionaba Lorenzo Giustiniani al final del siglo XVIII en su Saggio storico-critico sulla tipografia del regno di Napoli ${ }^{7}$.

La recopilación aparece, sin embargo, citada en el Censimento nazionale delle edizioni italiane del XVI secolo (EDIT16), donde está atribuida erróneamente a Juan de Vega, embajador de Carlos V en Roma en la corte de papa Paulo III, y virrey de Sicilia a partir de 1547.

De hecho, las palabras de Antonio Gargano, que, «entre burlas y veras», insinuó que el olvido del que fue objeto el volumen podría no imputarse exclusivamente a la injusticia de la historia, dada la no excelsa calidad de los textos $^{8}$, no restan a la colección de rimas su indiscutible valor documental en relación con el ambiente histórico y cultural en que se produjo.

El libro transmite 97 textos, la mayoría de los cuales son composiciones laudatorias dedicadas a los personajes más importantes de la nobleza de la corte virreinal, ya sean napolitanos o espańoles ${ }^{9}$. Se registran, sin embargo, también poesías de tema amoroso o mitológico, además de textos en los que el poeta habla de sí mismo, como en la epístola antes mencionada, pero es cierto que una de las características más relevantes del volumen es que se trata de un cancionero trilingüe.

6. El descubrimiento de los Versos de Juan de la Vega se debe, como ya se puntualizó, a la sabiduría del llorado maestro prof. Giorgio Fulco, que señaló generosamente el ejemplar conservado en la biblioteca napolitana a un grupo de amigos; véase Maria D’Agostino y Antonio Gargano, "Cancioneros plurilingües en el Nápoles español. Versos de Juan de la Vega (Mattia Cancer, 1552)", op. cit., p. 190, n. 2.

7. Véanse Pietro Manzi, La tipografia napoletana nel '500. Annali di Mattia Cancer ed eredi (1529-1595), Firenze, Leo S. Olschki Editore, 1972, y Lorenzo Giustiniani, Saggio storico-critico sulla tipografia del regno di Napoli, Napoli, Vincenzo Altobelli, 1793.

8. Maria D’Agostino y Antonio Gargano, «Cancioneros plurilingües en el Nápoles español. Versos de Juan de La Vega (Mattia Cancer, 1552)», op. cit., p. 190.

9. Para un elenco detallado de los destinatarios de los textos de Juan de la Vega, véase Maria D’Agostino y Antonio Gargano, «Cancioneros plurilingües en el Nápoles espańol. Versos de Juan de la Vega (Mattia Cancer, 1552)», op. cit., p. 193, n. 10. 
No me ocuparé en esta ocasión del carácter plurilingüe de los Versos de Juan de la Vega ${ }^{10}$, tipo de cancionero que participa de una tradición muy amplia y de larga duración que tuvo justo en Nápoles, y desde los Aragón, una de sus sedes más fecundas. Nos limitamos a recordar que esta tradición continuó más allá del cancionero de Juan de la Vega, al menos hasta finales del siglo XVI, con las antologías encomiásticas en honor de algunas damas napolitanas. Así ocurre con el Tempio alla divina signora donna Giovanna d'Aragona, una las damas napolitanas más presentes en la colección de Juan de la Vega, que vio la luz en 1555 y que fue «fabbricato -como reza el título- da tutti i più gentili spiriti $e$ in tutte le lingue principali del mondo», o sea, además de las lenguas clásicas, en italiano, francés y español. O también como sucede con la monumental recopilación dedicada a Giovanna Castriota, duquesa de Nocera, Rime et versi in lode della Ill.ma... Giovanna Castriota, que recoge composiciones en italiano, español y latín ${ }^{11}$.

Los Versos de Juan de la Vega se componen de 60 poemas en español, 28 en italiano y 9 en latín; cierra la recopilación un último texto en español, en endecasílabos sueltos. La colocación al final de una composición dirigida $A$ los versos parece responder a la intención de dar forma a la macroestructura de un libro de poemas; del mismo modo que la división en tres secciones, en español, italiano y latín, introducidas sistemáticamente por textos religiosos dedicados, respectivamente, a Dios, a la Virgen, a santa Lucía y a san Juan Bautista, y seguidos por composiciones encomiásticas dirigidas a don Pedro de Toledo, destinatario principal del volumen.

Si bien queda obscuro el criterio según el que se ordenaron en el libro los textos de tema amoroso o mitológico -admitiendo que ese criterio exista-, por lo que se refiere a las composiciones de carácter encomiástico no nos parece casual que estas se ordenen a menudo de acuerdo con la importancia política o de rango del destinatario. Por ejemplo, en la sección española, después del prólogo en octavas, los textos religiosos y las composiciones dedicadas a don

10. Véase, sin embargo, Maria D’Agostino y Antonio Gargano, «Cancioneros plurilingües en el Nápoles español. Versos de Juan de la Vega (Mattia Cancer, 1552)», op. cit., pp. 195-196 y la bibliografía allí citada.

11. Tempio alla divina signora donna Giovanna d'Aragona, Venezia, Plinio Pietrasanta, 1554; Rime et versi in lode della ill.ma et ecc.ma s.ra d.na Giovanna Castriota, Vico Equense, Giuseppe Cacchi, 1585. Sobre estas dos colecciones de versos véanse los estudios de Teresa Cirillo, "Valente Ercilla, mandami un sonetto": Rime in lode di Giovanna Castriota», Annali dell'Istituto Universitario Orientale di Napoli. Sezione Romanza, vol. 31, 1989, pp. 5-84; Tobia Toscano, «Le Rime di diversi illustri signori napoletani: preliminari d'indagine su una fortunata antologia", en Letterati, corti, accademie. La letteratura a Napoli nella prima metà del Cinquecento, Napoli, Loffredo Editore, 2000, pp. 183-200; Matteo Lefevre, «Lingua spagnola e italiana a confronto nelle antologie poetiche del secondo Cinquecento. Note su alcuni sonetti in castigliano di autori italiani nel Tempio per Giovanna D’Aragona e nelle Rime et versi per Giovanna Castriota Carafa», Philologia Hispalensis, vol. 19, 2005, pp. 51-7; y, ahora, y con especial atención a la segunda antología, Flavia Gherardi, “"D'esta heroica mujer [...] tu docta mano alto poema escriba”. Il codice eroico nelle Rime et versi in lode di Giovanna Castriota", Rivista di filologia e letterature ispaniche, en prensa; agradezco a la autora la lectura de su texto. 
Pedro, aparece un soneto enderezado a don García de Toledo, hijo del virrey y héroe de la expedición de África, seguido por textos dedicados, respectivamente, al duque de Sessa, al marqués de Mendoza y al mencionado mayordomo del virrey y protector del poeta Lope de Mardones.

Volveremos sobre esta «jerarquía» de las composiciones (y de los destinatarios), pero ahora queremos destacar una peculiaridad extremadamente relevante de nuestro cancionero y que, además de su plurilingüismo, despierta de inmediato la atención: la extrema variedad métrica de la colección.

$\mathrm{Si}$ es cierto que la mayoría de las composiciones que nos transmite son sonetos, exactamente un total de 73 , en la sección española se encuentran una composición en octavas, una oda, una canción, una doble sextina y una sextina, una égloga, la ya mencionada epístola en tercetos, y un capítulo en tercetos, además del texto $A$ los versos que, como se acaba de apuntar, se compone de endecasílabos sueltos. Una canción y un poema en octavas figuran también en la sección italiana en la que, sin embargo, se distinguen, cuatro madrigales, forma métrica que, evidentemente, Juan de la Vega practica pero que no se «atreve» a experimentar en español. Las composiciones en latín son, en orden sucesivo: una égloga en hexámetros, un epitalamio, un epicedio, dos poemas religiosos y una breve serie de composiciones laudatorias, todas en dísticos elegíacos, para concluir con un poema en alabanza de Lope Mardones en dísticos epódicos.

En efecto, si el volumen de Versos publicado en Nápoles en 1552 hubiese tenido la circulación que, evidentemente, no tuvo, al cancionero y a su autor se le reservaría un puesto de honor en la historia de la difusión de las formas poéticas italianizantes en España ${ }^{12}$.

Lo que no ha sido posible determinar con precisión son las fechas a las que remontan las composiciones incluidas en nuestro cancionero, pero, por los datos que algunos de los textos nos proporcionan, se puede afirmar que muchas fueron escritas después de 1547. Se trata, como se sabe, de un período convulso de la historia del virreinato, puesto que hablamos de los años que mediaron entre la revuelta napolitana de 1547 y la muerte de don Pedro. Reprimida la rebelión las autoridades estaban obsesionadas por la disidencia política o religiosa y reforzaron las medidas de control social e ideológico: los procesos se siguieron unos a otros y se produjo «una importante emigración política que se mostrará especialmente amenazante durante la gran crisis de $1552 »^{13}$.

Junto a una política de creciente control, don Pedro se preocupó también de promover acciones para reforzar y mejorar la imagen virreinal, muy comprometida después de la rebelión. Así pues, los Versos de Juan de la Vega

12. Para enmarcar la importancia que los Versos de Juan de la Vega hubiesen podido adquirir en el cuadro general de la difusión de las formas métricas italianizantes en la poesía española, véase Maria D’Agostino y Antonio Gargano, «Cancioneros plurilingües en el Nápoles español. Versos de Juan de la Vega (Mattia Cancer, 1552)», op. cit., pp. 197-198.

13. Carlos José Hernando Sánchez, Castilla y Nápoles en el siglo XVI. El virrey Pedro de Toledo. Linaje, estado y cultura (1532-1553), op. cit., p. 324. 
deben estudiarse dentro del marco de la propaganda política filotoledana promovida por el virrey sobre todo después de 1549 , con el objetivo de hacer olvidar a sus súbditos la violencia con que se había actuado en la sublevación de 1547 y volver a presentarse como un gobernante iluminado y magnánimo.

Sin volver sobre el denso programa de propaganda filotoledana llevado a cabo entre 1548 y $1552^{14}$, en el que se inserta también una calculada política editorial, así como sobre el hecho de que entre los intermediarios más activos de la «difusión cultural y propagandística de la imagen virreinal» ${ }^{15}$ figure Lope de Mardones, al que tan vinculado se presenta nuestro poeta, nos limitaremos a recordar que, aparte de las publicaciones promocionadas directamente por el virrey, la propaganda política se desarrolla también, como es de esperar, en los textos poéticos dedicados directamente a don Pedro, entre otros, por Luigi Tansillo, cuyos vínculos con el de Toledo y su familia son sobradamente conocidos, y por Laura Terracina ${ }^{16}$.

En su Discorso sopra tutti li primi canti dell'Orlando Furioso, que vio la luz en Venecia en 1549, la virtud del virrey es altamente ensalzada; en el soberano se funden la justicia ejemplar con la gentileza cortesana ${ }^{17}$. Y no parece que pueda considerarse una casualidad el hecho de que a las octavas sobre el Canto XVIII dedicadas al virrey sigan las dedicadas a Nápoles. En ellas, al igual que en algunos de los textos escritos por Tansillo después de 1547 y, por otra parte, en algunas composiciones de Juan de la Vega, se invita a la ciudad y a sus habitantes a reflexionar sobre las consecuencias que su actitud delictiva

14. Maria D’Agostino y Antonio Gargano, «Cancioneros plurilingües en el Nápoles español. Versos de Juan de la Vega (Mattia Cancer, 1552)», op. cit., pp. 194-195 y pp. 198-208.

15. Carlos José Hernando Sánchez, Castilla y Nápoles en el siglo XVI. El virrey Pedro de Toledo. Linaje, estado y cultura (1532-1553), op. cit., p. 324.

16. Para la política de propaganda desarrollada por el virrey, especialmente después de 1547 véanse, ibid., p. 395; Pietro Manzi, La tipografia napoletana nel Cinquecento, op. cit., I, pp. 88-89; Tobia Toscano, Contributo alla storia della tipografia a Napoli nella prima metà del Cinquecento (1503-1553), Napoli, E.DI.SU, 1992, pp. 64-65; Tobia Toscano, Letterati, corti, accademie. La letteratura a Napoli nella prima metà del Cinquecento, op. cit., p. 157. Para las obras de Tansillo dedicadas al virrey y a su entorno véanse Luigi Tansillo, Capitoli giocosi e satirici, ed., introd. y notas Carmine Boccia y Tobia Toscano, Roma, Bulzoni Editore, 2010; Luigi Tansillo, Rime, ed., introd. y notas Tobia Toscano, Erika Milburn y Rossano Petarino, Roma, Bulzoni Editore, 2011, 2 vols. Sobre Laura Terracina veánse, por lo menos, Benedetto Croce, «La casa di una poetessa», en Storie e leggende napoletane, ed., introd. y notas Giuseppe Galasso, Milano, Adelphi, 1990; Lina Maroi, Laura Terracina, poetessa napoletana del secolo XVI, Napoli, Perrella, 1913; Giulio Ferroni y Amedeo Quondam, La "locuzione artificiosa". Teoria ed esperienza della lirica a Napoli nell'età del Manierismo, Roma, Bulzoni, 1973; Amedeo Quondam, La parola nel labirinto. Società e scrittura del Manierismo a Napoli, Roma, Laterza, 1975; Gianluca Genovese, "Ariosto a Napoli. Vicende della ricezione del Furioso negli anni trenta e quaranta del Cinquecento", en Lina Bolzoni, "Tra mille carte vive ancor». Ricezione del Furioso tra immagini e parole, Lucca, Pacini Fazzi, 2010, pp. 339-356.

17. Discorso sopra tutti li primi canti dell'Orlando Furioso fatti per la Signora Laura Terracina, In Venetia appresso Gabriel Giolito di Ferrari. Este es el título de la princeps que, en las sucesivas ediciones, cambiará en Discorso sopra il principio di tutti i canti dell'Orlando Furioso, con el que se suele mencionar la obra más frecuentemente. 
puede desencadenar y a considerar también todo lo que don Pedro ha realizado dentro de los muros partenopeos ${ }^{18}$. Así como tampoco es una coincidencia que entre los destinatarios del Discorso de la Terracina figuren muchos miembros de las familias de Ávalos-Aragón y Aragón-Colonna que aparecen asimismo en nuestro libro de poemas.

Los Versos de Juan de la Vega se enmarcan evidentemente en un ambiente político y literario bien definido que explica también la ausencia de textos escritos a la manera tradicional por parte de un poeta español, aún más que la indudable herencia e indeleble memoria que Garcilaso había dejado en la ciudad partenopea, y que iba afirmándose en las letras españolas después de 1543. En efecto, una colección de poesías cuyo objetivo es, ante todo, el encomio de una clase dirigente ante sus súbditos y cortesanos tenía a la fuerza que utilizar unos medios expresivos, en este caso, métricos, que fueran familiares a sus lectores.

El virrey don Pedro de Toledo, en cuanto dedicatario del volumen, resulta, como era de esperar, el personaje al que se dirige el mayor número de composiciones. Sobre muchas de ellas y sobre la manera de representar la majestad del virrey por parte de Juan de la Vega ya nos detuvimos anteriormente ${ }^{19}$.

Lo que sí quisiera matizar en esta ocasión es que las familias de ÁvalosColonna y Aragón, que ya hemos mencionado, así como la de los Mendoza de Alarcón, adquirieron un peso cada vez mayor en la política interior del virreinato, y que este peso político queda claramente reflejado en los Versos.

Y esto no solo a nivel de la macroestructura del cancionero, en la que, como hemos dicho más arriba, las composiciones se ordenan en grupos que siguen una "jerarquía» política o de rango social, sino también a nivel de poemas sueltos. Un caso ejemplar en este sentido es el representado por el texto dedicado a la «Illustrissima Signora donna Leonora Sanseverino», verdadero microcancionero

18. Sobre las imponentes obras urbanísticas realizadas en Nápoles durante el virreinado de don Pedro de Toledo existe una amplísima bibliografía; véanse, por lo menos: Franzo Strazzullo, La città di Napoli dopo la riforma urbanistica di Pedro de Toledo, Roma, Editori G. e M. Benincasa, 1988, en donde se reproduce en edición facsímil la obra de Tarcagnota Del sito, et lodi della città di Napoli con una breve storia degli suoi re, et delle cose piu degne altrove né medesimi tempi avenute di Giovanni Tarcagnota di Gaeta, In Napoli: appresso Gi. Maria Scotto, 1566; Id., Edilizia e urbanistica a Napoli dal '500 al '700, Napoli, L'Arte Tipográfica, 1995 [1968]; Carlos José Hernando Sánchez, Castilla y Nápoles en el siglo XVI. El virrey Pedro de Toledo. Linaje, estado y cultura (1532-1553), op. cit, pp. 504-537 y la bibliografía allí citada e Id., «La cultura nobiliaria en el virreinato de Nápoles durante el siglo XVI», en Historia social, n 28, 1997, pp. 95-112. Véase también Maria D’Agostino, "L'alma de un gran valor ardiente en zelo". Don Pedro de Toledo nella poesia di Juan de la Vega», op. cit., pp. 418-420.

19. Véase Maria D’Agostino y Antonio Gargano, «Cancioneros plurilingües en el Nápoles espańol. Versos de Juan de la Vega (Mattia Cancer, 1552)», op. cit., pp. 201-208; Maria D’Agostino, "L'alma de un gran valor ardiente en zelo". Don Pedro de Toledo nella poesia di Juan de la Vega», op. cit.; Maria D’Agostino, «La representación de la 'majestad' en la poesía del reino de Nápoles en el siglo XVI. Continuidad e innovación», en Isabella Tomassetti, Tradizioni, modelli, intersezioni. La poesia castigliana fra XIV e XVII secolo, en prensa. 
o, mejor dicho, tempio de «Li Ritratti» dedicado a las más influyentes damas del reino y de la corte de don Pedro de Toledo ${ }^{20}$. Sin embargo, hay otro que, si bien no refleja a nivel microtextual la macroestructura de la recopilación de versos, desde el punto de vista de la propaganda política se revela aún más interesante.

Se trata de la ya mencionada Égloga Nice, que se edita aquí por primera vez, dedicada a Juana de Aragón y escrita en alabanza de Victoria Colonna de Aragón, esposa desde 1552 de don García de Toledo.

El texto, cuya rúbrica reza «Egloga Nice. En loor de la Señora doña Victoria Colona dirigida a la ilustrissima Duquesa Doña Juana de Aragón, su madre», representa, sin lugar a dudas, una de las composiciones más ambiciosas de la colección de versos ${ }^{21}$.

No es fácil determinar la fecha de redacción de la égloga, pero puede avanzarse la hipótesis de que se escribió entre junio de 1551 y los primeros meses de 1552, a juzgar por las referencias a hechos relacionados tanto con la biografía de Juana como con la de Victoria.

La obra se compone de 524 versos; se trata de una égloga polimétrica cuyo esquema es bastante complejo. Los primeros 64 versos se reparten en 4 estancias, seguidos de otros 51 versos - del 65 al 116- distribuidos en tercetos, a los que sigue una segunda serie de 4 estrofas. A esta sucede una secuencia de 24 octavas reales. La égloga se cierra con una tercera serie de estancias, concretamente 10 .

Las tres series de estrofas presentan esquemas métricos diferentes entre ellas. El primero y el tercero no aparecen ni en los Rerum Vulgarium Fragmenta ni los utilizan Juan Boscán y Garcilaso de la Vega, ni están registrados en el Repertorio metrico della canzone italiana ${ }^{22}$.

El hecho de que Juan de la Vega haya elegido para dos secciones del texto dos esquemas métricos no registrados -es decir, sobre todo a esas alturas cronológicas, si no originales, al menos sí raros- confirma el carácter experimental de su versificación, como ya se señaló a propósito de la canción Si alzar del hondo mar l'humida frente ${ }^{23}$.

20. Maria D’Agostino, “La nobil città de la sirena / più ch'altra di bellezza e gratia plena”. Los "Ritratti" de los Versos de Juan de la Vega», en Andrea Baldissera, Cancioneros del Siglo de Oro. Forma y formas, Actas del Congreso Internacional (Vercelli, 11-14 de octubre de 2016), en prensa. Utilizo el término tempio en el sentido que el lema adquirió a lo largo del siglo XVI para indicar también una colección de rimas diversas dirigida a uno o más destinatarios. La más famosa de estas colecciones fue el Tempio alla divina signora donna Giovanna d'Aragona ya mencionado en la n. 11.

21. De hecho, es una de las dos églogas escritas por Juan de la Vega, y es significativo que la otra, la Égloga Silenus, sea todavía más ambiciosa, puesto que es en latín y está dedicada a don Pedro de Toledo. Esto confirma que Victoria Colonna de Aragón era, en opinión de Juan de la Vega, la personalidad más representativa de la corte con vistas a la realización de su obra de propaganda.

22. Guglielmo Gorni, Repertorio metrico della canzone italiana dalle origini al Cinquecento, Firenze, Franco Cesati Editore, 2008.

23. Véase Maria D’Agostino, "L'alma de un gran valor ardiente en zelo". Don Pedro de Toledo nella poesia di Juan de la Vega», op. cit. p. 415. 
Distintas observaciones induce, al contrario, el esquema métrico de la segunda serie de estancias con el que se mide Juan de la Vega, puesto que es el mismo de la canción Chiare, fresche e dolci acque, retomado por Boscán en Claros y frescos ríos y, lo que más interesa aquí, en ámbito bucólico por lacopo Sannazaro en la Arcadia, égloga V, y por Garcilaso de la Vega, en los versos 3876 de su égloga II.

En efecto, y como era de esperar, es precisamente la obra maestra de Sannazaro y las tres églogas del gran toledano las que, sobre todo, atrajeron la atención de nuestro poeta a la hora de escribir su Égloga Nice ${ }^{24}$.

Antes de analizar la relación con las posibles fuentes que subyacen al diseño de la composición y comprobar hasta qué punto Juan de la Vega se adhiere a sus modelos o en qué medida se aleja de ellos, nos parece oportuno presentar el conjunto de la obra.

Los cinco esquemas métricos ilustrados permiten detectar una correspondencia entre metros utilizados y situaciones narrativas ${ }^{25}$. De hecho, el poema consta de cuatro partes: la dedicatoria, la descripción del escenario en el que se desarrolla la acción, el canto amebeo de dos pastores y el canto de Parthenope.

Sin embargo, aun siendo los que se acaban de apuntar los núcleos principales del texto, tanto la dedicatoria como el canto amebeo se articulan en dos momentos temáticos distintos, que en el segundo caso se identifican también gracias a un significativo cambio de metro ${ }^{26}$.

De hecho, la estancia I es una invocación del poeta a las musas para que le concedan el poder de relatar el canto de Philón y Tagontín, empeñados en «[...] loar una donzella / -obra más d'Airón digna y de Orpheo-» (v. 10); la dedicatoria empieza solo en la II estrofa, con la mención de la destinataria ${ }^{27}$ :

\footnotetext{
Vos, eccelsa, gentil, hermosa planta

digna cuanto él de vos de vuestro fructo, par en tierra sin par que imbidia el cielo, agora estéis buscando entre la sancta doctrina d'Elicona al grave lucto
}

24. No se olvide que Egloga Nice es también el título de la égloga IX de Bernardino Rota dedicada al nacimiento y alabanza de Vittoria Colonna, marquesa de Pescara, bajo cuyo «patrocinio» el poeta compuso sus Egloghe pescatorie. Véase, al menos, Bernardino Rota, Egloghe pescatorie, ed., introd. y notas Stefano Bianchi, Roma, Carocci, 2005.

25. Correspondencia frecuente en las églogas italianas de la época; véase Iacopo Sannazaro, Arcadia, ed., introd. y notas Carlo Vecce, Roma, Carocci, 2013, p. 91 y la bibliografía allí mencionada. Polimétrica, si bien menos articulada, es también la égloga II de Garcilaso, véase Garcilaso de la Vega, Obra poética y textos en prosa, op. cit., pp. 141-222.

26. Véase infra p. 659.

27. En efecto, también el esquema métrico de esta estancia es distinto de las otras tres que componen la primera serie; el hecho en sí es interesante, si bien, considerando que las referencias a la destinataria del texto se extienden también a las estrofas III y IV, no se puede afirmar con seguridad que Juan de la Vega haya querido, como en otros lugares de la composición, marcar con el cambio de metro una diferencia temática; nos limitamos a notar que cuando Juana de Aragón es mencionada por primera vez se utiliza un esquema de rimas que no vuelve en toda la composición. 


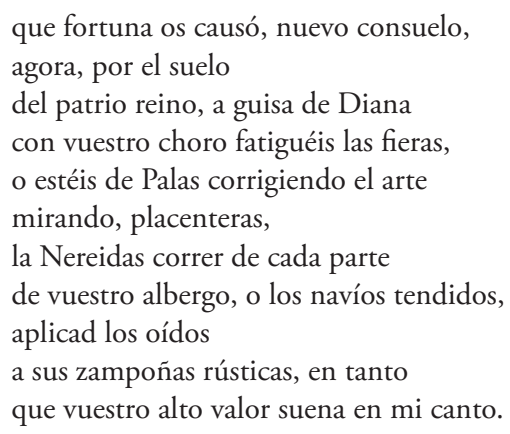

$\mathrm{La}$ «hermosa planta» que el poeta espera escuche atentamente el «son suave y los dulces acentos» de sus pastores, es, como se ha dicho, Juana de Aragón, alabada como una diosa. El poeta la asimila a Diana y a Palas. El símil de la diosa de la caza y su séquito, además de la loa que conlleva, se refiere probablemente al hecho de que la corte de Juana en Nápoles, la residencia de Castel dell'Ovo, así como la de Ischia -animada por la cuñada y célebre poetisa Vittoria Colonna, y en donde Juana residió muy a menudo después de la separación de su marido Ascanio- era lugar frecuentado por las más importantes damas del reino, entre otras por su hermana María de Aragón, viuda de Alfonso d'Ávalos, y por Giulia Gonzaga. Una hipótesis, esta, confirmada también por el otro símil que hace referencia a Palas, diosa de la sabiduría, educadora de doncellas en las artes, además de diosa de la guerra que, a diferencia de Marte, aprecia las victorias llevadas a cabo con la reflexión y la perseverancia.

Sin embargo, además de los significados que versos y símiles adquieren respecto a la laudanda, a ningún lector de poesía del siglo XVI puede escapársele -y menos aún a los de la corte de don Pedro de Toledo- el hecho de que la estancia que acabamos de citar es casi un calco de la segunda mitad de la estrofa I y de la II de la égloga I de Garcilaso.

A pesar de la fama que estos versos adquirieron en seguida, parece significativo el hecho de que, vivo todavía don Pedro, destinatario de los versos del toledano, y, además, en un volumen a él dedicado, Juan de la Vega utilice, para alabar a otro personaje, exactamente la estructura introducida por la anáfora de «agora» que, en los versos de Garcilaso, enumeraba las distintas ocupaciones a las que el virrey se dedicaba. Creo que no se trata de una casualidad, y que Juan de la Vega, de manera consciente, está elevando a Juana a una altura que trae inmediatamente a la memoria la figura de don Pedro, es decir, a un nivel que no tenía par en el reino.

Y las analogías no se limitan a la estructura y al tipo de tareas descritas en las segundas estancias de ambos textos -la caza y la guerra-, sino que se extienden a las estrofas III y IV del nuestro, en las que el poeta fija la mirada en la segunda parte de la II y III del texto garcilasiano. De hecho, Juan de la Vega, a pesar de las adversidades que Fortuna le ha proporcionado y si bien es consciente de las dificultades que las alas de su pluma puedan encontrar para «bolar» ante todas las que se empeñen en celebrar las virtudes de Juana -que "es peso» que 
cansaría hasta el mismo Atlante (v. 38)-, no quiere que la posteridad pueda pensar que su poesía haya callado la belleza absoluta de tal dama - «traslado» del Creador (v. 44)-, digna de tan «alta memoria» que si "el árbol de victoria» ciñe la frente de alguien, será porque ella es el objeto de sus versos (vv. 46-48).

Una «epopeya» de las virtudes, sabiduría y hermosura de Juana -en lugar de las garcilasianas «virtudes y famosas obras» de don Pedro- ${ }^{28}$, lo que aspiraría a componer un día Juan de la Vega - una "epopeya» "sub specie mulieris»- que de momento será compensada celebrando el digno "fructo» de esta nueva Palas, es decir, de $\mathrm{Nice}^{29}$.

Y a la alabanza de doña Victoria Colonna de Aragón están dedicados, de hecho, tanto el canto amebeo de Philón y Tagontín como el de Parténope. Antes de que tomen la palabra los dos pastores, sin embargo, el poeta describe el ambiente en el que se desarrolla la acción.

Un lugar donde hay un monte habitado por ninfas, sátiros, faunos y silvanos, «[...] lleno / de cuanto bien sembró natura» (v. 66), en cuya cima hay laureles, cipreses y vides, durante todo el año lleno de flores y plantas olorosas. Un lugar donde «[...] muestran su gozo los pastores / con silvestres acentos, y su pena» (vv. 77-78), al punto que todo el aire «va lleno de amores» (v. 79). Un lugar, en fin, que como se infiere de lo dicho, es absolutamente mítico y, sin embargo, profundamente real, puesto que se trata de un monte de Campania que el poeta, después de la descripción que acabamos de sintetizar, declara ser casi inútil intentar representar puesto que «[...] con decir Pausilipo se entiende / cuanto de honor le voy yo procurando» (vv. 87-88).

En la falda del monte que «[...] al pueblo mira / que aun de Parthenope el nombre defiende» (vv. 90-91), se encuentra Philón que, «armado de cayado y lira», mientras a la sombra de un pino vigila su ganado, ve llegar a Tagontín, "[...] el pastor más virtuoso / que del Ibero en el Sebetho vino», el cual le dirige la palabra deseándole que su descanso sea satisfactorio tal como el reposo al cual aspira su pecho, y que el pasto sea para su ganado tan provechoso cuanto lo ha sido para su alma la visión de su amada.

Philón responde devolviéndole los deseos con las siguientes palabras:

$$
\begin{aligned}
& \text { [...] «y tú, libre de enojos } \\
& \text { te veas d'amor, y las tuyas agenas } \\
& \text { de ser di Licaón hechas despojos; } \\
& \text { pon fin a tus palabras, que más llenas } \\
& \text { están de cortesía que del Tago, } \\
& \text { do tu naciste, d'oro las arenas, }
\end{aligned}
$$

28. Es probablemente superfluo recordar que en la III estancia de la égloga I, Garcilaso hace explicita referencia al hecho de que hasta que no logre escribir para don Pedro el poema que su «fama y su gloria» le merecen, el «árbol de victoria» que cińe la frente del virrey, cede el «lugar a la hiedra» de virgiliana memoria. Cf. Garcilaso de la Vega, Obra poética y textos en prosa, ed. Bienvenido Morros, Barcelona, Crítica, 1995, p. 122 y las notas correspondientes.

29. Recuérdese que en la mitología griega Nike es una de las manifestaciones de Palas-Atena. Véase Robert Graves, I miti greci, Milano, Loonganesi, 1987, p. 37. 
siéntate, y si en loar plazer te hago

cantando de tu Nice la belleça,

solo quiero de ti la ayuda en pago».

Aprendemos así que Tagontín nació a orillas del Tajo y que la dama cuya belleza le ha robado el corazón es Nice. El pastor, que, sin duda alguna, hay que identificar con don García de Toledo, acepta sin vacilaciones la invitación de Philón a loar la belleza de la dama.

Empieza así la tercera parte de la composición, caracterizada por el canto amebeo $^{30}$.

Las primeras 4 estancias de esta sección del texto en las que se alternan las voces de los dos pastores tienen un esquema métrico distinto de las octavas en las que se cantará la belleza de Victoria. La diferencia estriba en el tema: de hecho, estas estancias son la invocación de Philón y Tagontín para que se les conceda la fuerza necesaria para loar la sobrehumana hermosura de Nice, y se agrupan en dos unidades formadas cada una por dos estrofas. En la primera unidad, Philón invoca el Cielo, la Natura y Febo para que le inspiren «concectos iguales» a las "gracias inmortales» de Nice (vv. 129-130), y Tagontín se dirige con laudes hiperbólicas directamente a la amada, considerado que "pues es vuestro el sujeto / espirad en mí dél digno concecto» (vv. 142-143). En la segunda unidad, las divinidades invocadas "responden" llenando, respectivamente, «del humor [...] d'Elicona» la seca vena del primer pastor, y de "gracia» el pecho del segundo (v. 169).

En las veinticuatro octavas que siguen, Philón y Tagontín describen tanto la belleza exterior de Nice como la de sus virtudes interiores, a las que se debe la hermosura de su "gentil velo», según una interpretación canónicamente platónica de la belleza.

La descripción física de la dama se realiza empezando por los cabellos hasta llegar a las «blancas manos» pasando, en sentido descendente, por la frente, los ojos, las mejillas, la nariz, la boca y el cuello. Imposible en esta circunstancia dar cuenta pormenorizada de la riqueza de imágenes que el poeta utiliza para cada una de las partes del cuerpo de Nice, en las que se concretan dos siglos de variaciones sobre el «canone breve» de la belleza femenina ${ }^{31}$. Juan de la Vega ha

30. Es probable que Juan de la Vega, al escribir esta tercera parte de la égloga, tuviese en cuenta la II prosa y la segunda égloga de la Arcadia de Sannazaro, en donde Montano, después de una significativa referencia a los lobos enemigos de los ganados, invita a Uranio «a cantare con lui, cosa che Uranio fa con piacere, improvvisando una strofa responsiva a ogni strofa che gli propone Montano»; véase Iacopo Sannazaro, Arcadia, op. cit., p. 90; mientras para los textos y las notas ibid., pp. 76-91.

31. La bibliografía sobre el asíllamado «canone breve» es especialmente vasta; véanse por lo menos, Giovanni Pozzi, La rosa in mano al professore, Friburgo, Edizioni Universitarie di Friburgo, 1974; Id., Sull'orlo del visibile parlare, Milano, Adelphi, 1993, pp. 145-171 y pp. 173184; Id., Alternatim, Milano, Adelphi, 1996, pp. 449-526, y Amedeo Quondam, «Il naso di Laura: considerazioni sul ritratto poetico e la comunicazione lirica", en Id., Il naso di Laura. Lingua e poesia lirica nella tradizione del Classicismo, Ferrara, Franco Cosimo Panini Editore, 1991, pp. 291-328. 
vertido en estos versos todas sus posibilidades expresivas y sus conocimientos clásicos, sin olvidar nunca, sin embargo, la "realidad" histórica del personaje al que está alabando, y así, en el verso 267 se menciona en un símil «el templo de Mergilina», en donde Nice ofrece «blanca cera» al «bien de los humanos» (vv. 267-268) ${ }^{32}$.

A partir del verso 322, acabado el elogio de Tagontín relativo a las virtudes del alma de Nice y de sus benéficos efectos sobre él (cf. Apéndice, n. 50), las alabanzas de los dos pastores a Victoria se hacen hiperbólicas: ella -«que con las cartas de Apolo se acompaña»- supera en sabiduría y en artes a la principales diosas; el don que Tagontín le ha hecho -es decir el de su alma- no tiene parangón con los regalos de los demás pastores para sus amadas; quien ama «su gesto» no podría amar en ningún caso a otra ninfa, como suele ocurrir a algunos dioses, afirmación, esta, por medio de la cual la loa se dirige también, aunque indirectamente, al mismo Tagontín y a su fidelidad.

Por fin, si Samo, Atena, Cynthia y Chipre honran y adoran respectivamente a Juno, a Palas, a Diana y a Venus, Parténope puede dirigir a estas ciudades la siguientes palabras: «[...] si llenas / de jatancia os mostráis por las que os moran / a Cipro escurecer puede mi gloria, / a Samo, a Cynthia, a Athenas, por Victoria» (vv. 350-352).

A estos versos sigue la última octava de la tercera parte del texto, que cumple la función de transición entre el canto de los dos pastores y el de Parténope, protagonista de la serie final de estancias de que se compone la égloga, con la profecía sobre el destino de $\mathrm{Nice}^{33}$.

La «docta sirena», que sentada en la arena «había estado escuchando» a Philón y Tagontín, toma la palabra e invita a todas las ninfas, musas, nereidas, dríades, amadríades y napeas ${ }^{34}$ a unir sus danzas y a alegrarse con ella para admirar el «nuevo sol»-es decir, Nice- gracias al que «[...] Sebetho ameno irá y altivo, / y el Tiber embidioso, qu'es dél privo» (vv. 374-375). A partir de la segunda estancia, Parténope se dirige directamente a la laudanda, definiéndola «[...] nimpha real, digna de imperio» e invitándola a fijarse en como su "clara origen" se ornará con la virtud de gente noble «[...] qu'en el mundo par no tiene, / cuya alteza ilustró nuestro hemisperio / d'agudo hierro y de valor armada» (vv. 381-383).

32. Es probable que Juan de la Vega aluda a la iglesia de Santa Maria del Parto a Mergellina, en donde se encuentra el monumento fúnebre de Sannazaro.

33. Desde el punto de vista de la estructura general de esta última parte de la égloga, hay que destacar que las primeras 8 estancias presentan al final el estribillo «Corred, pues es el fin, nimphas, Victoria», a imitación de la estructura de las primeras once estrofas que componen el canto de Salicio en la égloga I de Garcilaso de la Vega. Este, como es notorio, fijó a su vez la mirada en la bucólica VIII de Virgilio, imitado por Sannazaro en Arcadia, XI ${ }^{e}$, a partir del verso 22. El uso del estribillo obliga a nuestro poeta a una rima en -oria debido al nombre de la laudanda, y es significativo que las palabras que riman con Victoria sean, además de "gloria» (muy utilizada ya desde la poesía cancioneril del XV), «historia» y «memoria», como para rematar que la grandeza de Nice será eterna.

34. Para estos versos y el orden en que los míticos personajes se mencionan, véase Iacopo Sannazaro, Arcadia, op. cit., VIII, 47. 
Queremos ilustrar, aunque brevemente, los extraordinarios elogios que Parténope dirige a Victoria en las estancias III-VI: todos los rasgos físicos, alabados por Philón y Tagontín en las octavas del canto amebeo, se repiten con concisión en las palabras de la sirena. A estos se añaden las virtudes interiores, especialmente las de justicia, con que le ha favorecido Astrea en persona. Gracias a ellas no solo los humanos pueden entender «la beldad de la causa primera», sino que quien se enamora de ella «ni es ya mortal» (v. 419).

La naturaleza entera revive para celebrar a Nice, las Musas «trahen vasos d'humor del Elicona / con las cartas de Apollo [...]» (vv. 445-446) para que aprenda y para coronarla de laurel; Palas, "docta», le enseńa sus artes, y el mundo entero la adora y construye aras para perpetuar su memoria, siendo Victoria «del mundo vencedora».

Las estrofas VII y VIII del canto de la sirena ya no se refieren a la hermosura y grandeza de Nice, sino que cuentan cómo Némesis, en nombre de Victoria, al mando de una nave cargada de todos los bienes que Fortuna puede donar, no se da cuenta de la llegada imprevista de una tormenta y, «arrebatada» por vientos contrarios que vencen los propicios, tiene que seguir otro camino, acabando por ser "presa de un vecino / y saqueada", puesto "que de vera gloria / en tierra no hay destino» (v. 474-475). Causa de tal daño es la «enemiga Fortuna», su "mutable estado" que quita "lo alto a quien le toca» para darlo a quien no lo merece, como ha hecho en el caso de Victoria, con el único objetivo de mostrar que su crueldad puede ser tan grande como lo es la belleza de esta, a la cual, escribe Juan de la Vega, «moviste nueva guerra / por dar a otro su estado / a que lo mande» (vv. 486-487); sin embargo, será la misma ninfa quien lo recuperará. Y de hecho, en la estancia IX Parténope pronuncia la siguiente profecía:

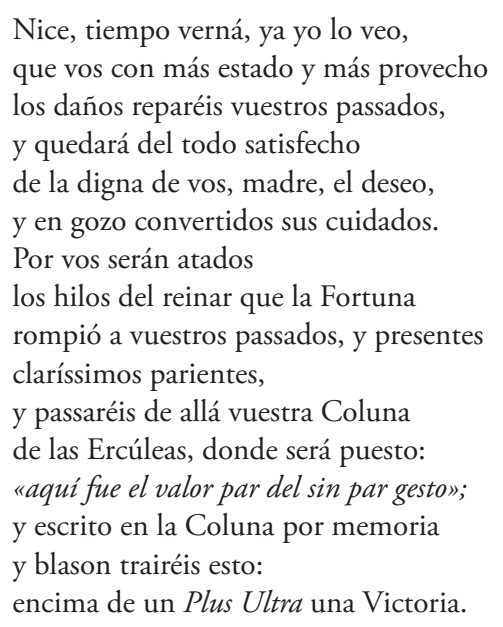

Con la estancia sucesiva, la llegada de la puesta del sol empuja las ninfas y pastores, que hubiesen querido seguir escuchando el «sabroso canto» de Parténope, a tomar cada uno "su via»; también el coro de las nereidas, que, 
llegadas «junto a Megari», levantaron un grito diciendo: «adiós, de beldad nido, / adiós, más que otro alguno venturoso» (v. 521-522) 35 .

Después de este recorrido a través del texto, y sin poder ahondar más en esta ocasión en el análisis de pasajes concretos, ha llegado el momento de avanzar una hipótesis interpretativa del conjunto de la composición tanto por lo que se refiere a las adversas circunstancias biográficas de Victoria y su madre, a las que parecen aludir las estancias finales -y sobre las que Nice triunfará-, como al significado que la égloga adquiere en su conjunto, más allá de la alabanza rendida a la dama.

Como adelantábamos, creemos que el texto se redactó entre 1551 y los primeros meses de 1552 .

Más indicios nos inducen a fijar esta como fecha de composición. El primero se encuentra en el verso 21 , cuando el poeta dirigiéndose a Juana se refiere al "grave lucto / que fortuna os causó». La pérdida aludida puede ser la del hijo Fabrizio Colonna, muerto en el mes de junio de 1551, durante la campaña militar contra Parma siguiendo a Ferrante Gonzaga ${ }^{36}$. Sin embargo, es el tema mismo de la égloga, es decir la exaltación de Victoria, como si se tratara de la mujer destinada a engrandecer aún más el reino, la que induce a pensar en esta fecha.

De hecho, es en 1551 cuando se firmaron las capitulaciones matrimoniales entre Ascanio Colonna y García de Toledo ${ }^{37}$, y en los primeros meses de 1552 cuando se celebró la boda, y no extraña que, en un volumen de versos destinado a celebrar a don Pedro y a su familia y que vio la luz precisamente en este ańo, la esposa del primogénito se torne objeto de especial alabanza; sobre todo si, gracias a esta boda, el virrey se vinculaba a uno de los linajes más antiguos de Italia y al más sólido sostén de la política hispano-imperial: los Colonna ${ }^{38}$.

35. «Megari» alude al nombre de la antigua pequeña isla de Megaride, en donde surge el Castel dell'Ovo y en donde llegaron los griegos que fundaron Nápoles. Ya se ha recordado que en esta isla Juana de Aragón tenía una de sus residencias.

36. Fabrizio Colonna se había casado en 1548 con Ippolita Gonzaga, hija de Ferrante Gonzaga e Isabella di Capua.

37. En el acuerdo se establecía también el valor de la dote, cincuenta mil escudos de oro, que Ascanio hubiese tenido que pagar en tres años; véase Carlos Hernándo Sánchez, Castilla y Nápoles en el siglo XVI. El virrey Pedro de Toledo. Linaje, estado y cultura (1532-1553), op. cit., p. 95.

38. «Vittoria proporcionaba a la familia del virrey el entronque con uno de los más prestigiosos linajes italianos, a cuya trayectoria hispanófila se unía una sólida tradición de mecenazgo. El padre de Vittoria, Ascanio, duque de Tagliacozzo y Gran Condestable del Reino de Nápoles, se había casado en 1521 con Juana de Aragón, hija de Ferrante, duque de Montalto y bastardo del rey Ferrante I, una de las mujeres más cultas de su tiempo. La boda de don García presentaba por tanto todos los rasgos de un nuevo triunfo matrimonial del Virrey, en una triple dimensión económica, política y de prestigio, que, pese a los problemas surgidos tras la muerte de don Pedro, suscitó en el momento la más honda alegría en el círculo de los Toledo», ibid., p. 96. 
El hecho de que en la parte central de la composición Tagontín / don García se dedique a celebrar la grandeza de Nice y los beneficios que el amor a ella le proporcionan, creo que confirma la hipótesis de la fecha y la ocasión de redacción del texto ${ }^{39}$.

Sin embargo, la Égloga Nice tiene, en mi opinión, un significado de propaganda política que va aún más allá de la celebración del matrimonio.

No se olvide que Victoria era por parte de madre, si bien por vía ilegítima, descendiente de los reyes de Nápoles -recuérdese la «clara origen»-, es decir, de aquella dinastía cuya caída había representado para los napolitanos, en palabras de Pietro Giannone, la pérdida del "pregio di avere re propri e nazionali»" ${ }^{40}$.

En un momento de grave crisis, como con la que tuvo que enfrentarse don Pedro después de 1547, la esposa de don García justificaba, aún más de lo perceptible en otros textos ${ }^{41}$, que en el imaginario colectivo los Toledo estuvieran vinculados a la ciudad, y lo hacía poniendo en escena los «mitos domésticos» que, durante el periodo aragonés, se habían inventado o recuperado, empezando por el de Parténope ${ }^{42}$.

39. El mismo año vio la luz La Nice di messer Luca Contile, breuemente comentata dal signor caualiero Vendramini. In Milano: per Valerio, \& Girolamo fratelli da Meda, adi 6. del mese de luglio, 1551, larga composición en endecasílabos sueltos también dedicada a Vittoria Colonna de Aragón. La égloga se había representado en este mismo año con ocasión de la visita a Ferrante Gonzaga del cardenal Ercole Gonzaga. Se trata de un texto muy descriptivo, a menudo pedante, que relata fábulas mitológicas trágicas seguidas por la metamorfosis del héroe y que solo en los versos finales presenta motivos de interés que podrían coincidir con las circunstancias biográficas de Vittoria que se suponen presentes en nuestro texto; coincidencias sobre las que se volverá en otra ocasión. Lo que ahora se desea subrayar es la fecha de la publicación, relacionada, probablemente también en este caso, con la noticia de las bodas entre Vittoria y García de Toledo. Contile dedicó la obrita a Felipe II subrayando en la dedicatoria al príncipe, protector de don García, cómo el de Nápoles «sia più degli altri regni per ogni merito degnissimo» y cómo dentro de sus confines se ha «nodrita e allevata donna Vittoria Colona Aragona». En la dedicatoria "A la unica donna Vittoria Colonna Aragona», el poeta construye símiles entre la dama, Iasón y Alcide, elevándola, como en el caso de nuestro texto, a la altura de los dioses. Sobre Luca Contile véase, por lo menos, Amedeo Quondam (ed.), Luca Contile. Uomo di lettere e negozi del XVI secolo, Roma, Bulzoni, 2008; Roberto Giugliucci (ed.), Luca Contile. Da Cetona all'Europa. Atti del Convegno di Studi (Cetona, 20-21 ottobre 2007), Roma, Vecchiarelli, 2009.

40. Citado por Giuseppe Galasso, Storia del Regno di Napoli, Torino Utet, 2011, vol. II, p. 176.

41. Véase Maria D’Agostino, «La representación de la 'majestad' en la poesía del reino de Nápoles en el siglo XVI. Continuidad e innovación», op. cit.

42. Sobre la construcción de una nueva y mítica imagen de Nápoles y sus alrededores en época aragonesa, véase Giuseppe Germano, "Giovanni Pontano e la costituzione di una nuova Grecia nella rappresentazione letteraria del Regno Aragonese», Spolia. Journal of medieval studies. Essays, 2015, http://www.spolia.it/online/it/edizioni_spolia/catalogo/documents/spolia2015.pdf, y la bibliografía citada, mientras para las modalidades de representación de la majestad durante el periodo aragonés, véase Joana Barreto, La majesté en images. Portraits du pouvoir dans la Naples des Aragon, Roma, École Française de Rome, 2013. La definición de «mito domestico» se toma de Donatella Coppini, "Pontano e il mito domestico», en Virginie Leroux (ed.), La Mythologie Classique dans la Littérature Néo-Latine. En hommage à Geneviève et Guy Demerson, ClermontFerrand, Presses Universitaires Blaise Pascal, 2011, pp. 271-292. 
De hecho, la representación de la majestad del virrey y de su familia cambia mucho a lo largo de las tres fases en las que es posible dividir su gobierno, especialmente entre la primera y la última ${ }^{43}$.

Y si en la primera, en un momento difícil pero de grandes esperanzas, la construcción del «estado Albano» había sido celebrada sobre todo gracias al genio universal de Garcilaso, que, entre los innumerables logros de su poesía, había "desplazado" la «nueva arcadia» de Pontano y Sannazaro a Castilla -es decir, del Sebeto al Tajo- con el principal objetivo de celebrar a los héroes de la «tierra d'Alba» -en donde "se halla lo que se desea: / virtud, linaje, haber y todo cuanto / bien de natura o de fortuna sea» (vv. 1056-1058)»-, ahora, en los años de crisis sucesivos al ' 47 , los poetas recorren con sus ninfas y pastores el camino inverso ${ }^{44}$.

Y la razón de esta vuelta atrás estriba precisamente en la necesidad de construir una imagen del virrey y de su familia que fuese en sintonía con el imaginario de sus súbditos en un momento de máxima tensión.

En nuestro texto, Tagontín -nótese la annominatio de Tajo para el nombre de don García- es «[...] el pastor más virtuoso / que del Ibero en el Sebetho vino» (vv. 96-96), porque es precisamente en las orillas del mítico río de Parténope en donde se encuentra la ninfa más virtuosa, la que, junto con su marido, logrará pasar con su «Coluna» más allá de las de Hércules, acompañada por un blasón que sobre el antiguo mote Plus ultra-es decir, del mote del mismo emperador Carlos V- llevará una «Victoria».

Casi un destino «imperial» lo anunciado por la sirena Parténope, que, si bien debe leerse en la dimensión laudatoria del texto, no resta fuerza al mensaje político tanto en la dimensión local napolitana como en el delicado equilibrio italiano. De hecho, la pareja Colonna de Aragón-Toledo representaba también la prolongación hacia Roma de la influencia de don Pedro, puesto que los Colonna tenían unas «extensísimas posesiones, estratégicamente situadas en los confines romanos-napolitanos, y un poderoso grupo de presión en la capital pontificia» ${ }^{45}$.

Y es a estas «posesiones», que fueron objeto de continuas tensiones entre Ascanio Colonna y el papado, especialmente durante los pontificados de Paolo III (1534-1549) y de Paolo IV (1555-1559), a las que se refiere, probablemente,

43. En el gobierno napolitano de don Pedro se suelen identificar tres fases distintas: la primera, que va de 1532 a 1536, ańos de la llegada del virrey a la capital del reino y de la estancia en la misma del emperador, respectivamente; la segunda, de 1537 a 1547, en la que se desarrolló la así llamada «svolta assolutistica», que culminó con la revolución de 1547 y los nuevos equilibrios entre nobleza y virrey a los que esta dio lugar; y la tercera, de 1548 a 1553, año de la muerte de don Pedro.

44. Este camino inverso es evidente en la producción de Luigi Tansillo como en la de Laura Terracina, además de ejemplificarse en numerosos textos de Juan de la Vega. Véase a este respecto Maria D’Agostino, «La representación de la 'majestad' en la poesía del reino de Nápoles en el siglo XVI. Continuidad e innovación”, op. cit.

45. Carlos José Hernando Sánchez, Castilla y Nápoles en el siglo XVI. El virrey Pedro de Toledo. Linaje, estado y cultura (1532-1553), op. cit., p. 96. 
Juan de la Vega en más de un lugar de la composición ${ }^{46}$. De hecho, aun cuando en 1550 Giulio III reintegró al Colonna la mayoría de sus territorios del Lazio, no disminuyó la conflictividad entre este y su esposa Juana, que le reprochaba, entre otras cosas, la pésima administración de los bienes de la familia y que contaba con el apoyo de sus hijos, especialmente Marcantonio y Vittoria ${ }^{47}$.

El Colonna, probablemente también debido a los conflictos con Juana y sus hijos, no entregó nunca a don García la dote que habían establecido ${ }^{48}$, y la tensión con su familia aumentó tanto que Ascanio llegó en 1552 a desheredar a Marcantonio y a definir a su esposa «inobediens, inimica et rebellis» ${ }^{49}$.

Es posible que el «Licaón», que Philón espera no haga «despojos» de las ovejas de Tagontín, sea una referencia a Ascanio y al pago de la dote de Vittoria en el tiempo previsto, y, sobre todo, que a las tensiones entre Ascanio y Juana, que apoyaba a Marcantonio, aludan los versos 493-499, en los que Parténope anuncia el tiempo en que Nice remediará los daños «[...] passados / y quedará del todo satisfecho / de la digna de vos madre el deseo, / y en gozo convertidos sus cuidados» (vv. 494-496).

46. Sobre las continuas tensiones entre Ascanio Colonna y el papado, véase, por lo menos, Franca Petrucci, «Colonna, Ascanio», en Dizionario Biografico degli Italiani, Roma, Istituto Enciclopedico Treccani, 1982, vol. XXVII, pp. 271-275, y la bibliografía allí mencionada.

47. Para la biografía de Juana de Aragón, véanse, Giuseppe Alberico, «Aragona, Giovanna», en Dizionario Biografico degli Italiani, Roma, Istituto Enciclopedico Treccani, vol. III, pp. 694697, y, más recientemente, el perfil trazado por Nicoletta Bazzano, «Giovanna d'Aragona: ritratti di gentildonna tra idealizzazioni letterarie e tensioni religiose», en José Martínez Milán, Manuel Rivero Rodríguez, Gijs Versteegen (eds.), La Corte en Europa: política y religión (siglos XVIXVIII), Madrid, Ediciones Polifemo, 2012, vol. III, pp. 1495-1510, donde se recoge también la bibliografía sobre su recorrido vital y político. Juana de Aragón se había separado de su marido Ascanio ya en 1535, inmediatamente después del nacimiento de su hijo Marcantonio. Debido al alto rango de los dos esposos, la separación tuvo un eco muy grande en la contemporánea nobleza italo-espańola y en la misma corte imperial, y fueron muchas las tentativas para lograr que Juana volviese sobre sus pasos. Ya en 1539 Ascanio Colonna «ottenne che il compito di persuaderla fosse affidato ad uno dei primi membri della nuova Compagnia di Gesù», y Loyola envió al padre Bobadilla; sin embargo, la entrevista no tuvo el éxito esperado. Juana se quejaba no solo del carácter agresivo de su marido para con ella y los hijos, sino que también le reprochaba «la sua improvvida amministrazione dei beni di famiglia e la politica eccessivamente arrischiata che egli conduceva». Tentativas para que la pareja se reconciliase se dieron por iniciativa del mismo Loyola en 1541, en 1543 y en 1549, pero no tuvieron el éxito esperado, también porque «la posizione dell'Aragona si era nel frattempo consolidata per la completa solidarietà stabilitasi tra lei e il figlio Marcantonio, che andava assumendo un atteggiamento sempre più nettamente ostile al padre [...]». En 1552 el mismo Ignacio de Loyola decidió visitar a Juana en el castillo de los Cardona en Altovito, pero el éxito de la visita no fue diferente al de las tentativas anteriores. Para las citas, véase Giuseppe Alberico, «Aragona, Giovanna», op. cit., p. 695.

48. En efecto «las negociaciones sobre el pago de la dote duraron varios años, dando lugar a una polémica que, finalmente, requeriría la intervención de la Corona, ya muerto don Pedro", Carlos Hernando Sánchez, Castilla y Nápoles en el siglo XVI. El virrey Pedro de Toledo. Linaje, estado y cultura (1532-1553), op. cit., p. 95.

49. Citado por Franca Petrucci, «Colonna, Ascanio», op. cit., p. 274. 
Lo que es cierto es que la Égloga Nice de Juan de la Vega representa, también por las fechas en la que probablemente se redactó, si no el último, uno de los últimos textos bucólicos escritos en Nápoles durante el virreinato de don Pedro, y a pesar de no ser Juan de la Vega poeta refinado y genial como otros que le precedieron o le rodearon en la corte virreinal, su composición permite confirmar la vitalidad de un género como la égloga en el Renacimiento napolitano y también reafirmar la honda vocación política y de propaganda del mismo ${ }^{50}$; precisamente la que necesitaba el gobernador del «estado Albano» en el ocaso de su poder $-\mathrm{y}$ de su vida-, también a través de la celebración de una nuera presentada como una verdadera Nike (vv. 382-391):

\author{
La frente coronada \\ d'oliva, palma, de laurel y d'oro, \\ en carro triunphal del mil areos \\ hostiles y tropheos \\ rodeada, y seguida de un gran choro, \\ d'encadenadas y diversas gentes \\ a quien Sebetho y Tyber, conoscientes \\ que habíades vos de ser de Italia gloria \\ decían, como presentes: \\ corred pues es el fin, nimphas, Victoria. ${ }^{51}$
}

\footnotetext{
50. Imposible dar cuenta aquí de la extensa bibliografía sobre la égloga relativa al periodo que va desde la segunda mitad del siglo XV a los años que nos interesan. Nos limitaremos a señalar algunos de los estudios de conjunto más significativos de donde el lector podrá extraer todas las referencias necesarias. Para la bibliografía sobre la Arcadia de Iacopo Sannazaro, véase la edición de Carlo Vecce a la que nos hemos referido a lo largo del texto, mientras que para un análisis del desarrollo del género en Nápoles entre el siglo XV y la primera mitad del XVI, puede consultarse Antonio Gargano, "L'egloga a Napoli fra Sannazaro e Garcilaso», en Con accordato canto. Studi sulla poesia tra Italia e Spagna nei secoli XV-XVII, Napoli, Liguori, 2005, pp. 181-202, y la exhaustiva bibliografía allí recogida. Para las églogas de Garcilaso de la Vega se remite a los estudios señalados en la edición de Bienvenido Morros, a la que nos hemos referido sistemáticamente. Por lo que se refiere a la lectura política de las églogas del gran toledano, especialmente de la égloga II, y a las relaciones que estas mantienen con sus principales modelos, sobre todo con Virgilio y Sannazaro, también desde un punto de vista teórico por lo que se refiere al género, véase el ensayo de Antonio Gargano en este volumen; del mismo autor: "Las estrañas virtudes y hazañas de los hombres". Épica y panegírico en la Égloga Segunda de Garcilaso de la Vega», Criticón, no 115, 2012, pp. 11-43. Por último, señalaré el reciente trabajo de Marco Santagata, Pastorale modenese. Boiardo, i poeti e la lotta politica, Bologna Il Mulino, 2016.

51. El carro triunfal, el laurel, la palma y los despojos de los enemigos son los atributos con los que, desde la antigüedad, antes griega y luego romana, se solía representar la Nike.
} 


\section{ApÉNDICE \\ Égloga Nice}

En loor de la señora dońa Victoria Colona dirigida a la illustríssima duquesa doña Juana d'Aragón, su madre

Versos1-64,estancias:I,III,IV:ABCABCcDEFeFDdGG;II:ABCABCcDEFeFGgHH; versos 65-116 tercetos; versos 117-169 estancias: abCabCcdeeDfF; versos 170-362 octavas reales; versos 363-526 estancias: ABCBACcDEeDFFGfG.

5

10
El son suave, y los dulces acentos ${ }^{52}$ los concectos no humildes inflamados en zelo de llegar a l'alta cumbre el merecer do, aun con los pensamientos, no llegan los juizios más cendrados sin especial favor de eterna lumbre con que tenían costumbre Philós y Tagontín, moços pastores, cantando de loar una donzella -obra más d'Arión digna y d'Orpheotal que quien podrá vella me dirá, con razón, ahora te creo; y aun d'otros, si pudiessen ser mejores diré, si los favores vuestros, hijas de Jove, en quien confío las alas alçarán del poder mío.

Vos, eccelsa, gentil, hermosa planta digna cuanto él de vos de vuestro fructo par en tierra sin par que imbidia el cielo,

52. La composición está transmitida por los ff. D6v- FIIIv. La grafía elegida es la del testimonio; las intervenciones se han limitado a los siguientes casos:

- se han resuelto las abreviaturas;

- se ha regularizado el uso de $u$ y $v$;

- se han regularizado $i, j$ según su valor vocálico o consonántico;

- se ha regularizado el uso de $m$ ante $b$ y $p$;

- se ha regularizado según los usos actuales la secuencia de vocal $+i$;

- se han distinguido mayúsculas y minúsculas;

- se han introducido la acentuación y la puntuación según el uso actual.

Las adiciones se señalan con paréntesis cuadrados ([...]). El signo de aféresis de la vocal final, en los encuentros vocálicos de fonemas idénticos y donde la regularidad del verso exige la sinalefa, está con frecuencia atestiguado por el impreso.

El texto presenta un elevado número de grafías "cultas" que se ha optado por respetar a pesar de no tener valor fonético, puesto que su uso parece deberse al interés del autor por dar un tono más elevado a la composición. Es este un usus detectable en todo el volumen de los Versos de Juan de la Vega, y especialmente frecuente en el caso de composiciones adscritas a géneros clásicos, como la égloga. 
agora estéis buscando entre la sancta doctrina d'Elicona al grave lucto que fortuna os causó, nuevo consuelo, agora, por el suelo o estéis de Palas corrigiendo el arte mirando placenteras

la Nereidas correr de cada parte de vuestro albergo, o los navíos tendidos, aplicad los oídos

a sus zampońas rústicas, en tanto que vuestro alto valor suena en mi canto.

Y bien que no hayan menester mi pluma las alas de la eccelsa fama vuestra para bolar de toda otra adelante, y de vuestros lo[o] res la gran suma, ${ }^{53}$ es peso de cansar, no que la nuestra pero la sin igual fuerça de Athlante, verme siempre delante

de tal empresa, la esperada gloria hará que nunca arguya a mi escritura el siglo venidero haber callado vuestra gran hermosura, propio del hazedor suyo traslado, sola digna en mi edad d'alta memoria. $\mathrm{Y}$, si árbol de victoria prometerá a su frente algún concecto, será que seréis vos del el sujeto.

Aunque toda su fuerça ha en mí probado Fortuna, y sepultado en el olvido me tiene de mí propio, y de las gentes que me han del patrio Tajo desterrado, y por estrañas partes me ha traído -renovando en mí exemplos muy dolientes-, cuando fueron presentes del bien del cielo mis ojos mortales, bendixe el mal que causó un bien tamaño, y estimé cuanto puede desviarme Fortuna en poco daño, como no pueda solo el bien quitarme de celebrar sus gracias inmortales, bien veréis las señales d'este deseo en los no ajenos lores, dignando'os de escuchar essos pastores.

53. loores] lores; la composición presenta sistemáticamente la forma «lores» sobre la que no se ha intervenido; en este caso se enmienda el texto para evitar la hipometría. 
Tiene entre otros Campania un monte lleno de todo cuanto bien sembró natura las espaldas, la halda, el ancho seno cuya frente corona una espessura de fructíferas plantas do esplendiente se ve quien Phebo amó en nuestra figura; el fúnebre Ciprés luego eminente, y tu planta gentil, padre Thebano, con la que junto al Gange ornó tu frente.

Encima tiene siempre un verde llano de hiervas olorosas lleno, y flores, estío, octońo, invierno, y el verano.

Assí muestran su gozo los pastores con silvestres acentos, y su pena: todo aquel aire va lleno de amores.

Allí suavemente Philomena, su lamento y successos inhumanos con las rústicas fístulas consuena,

a cuyo son los dioses por las manos asidos con las nimphas van bailando, los sátiros, los faunos, los silvanos;

¿A qué voy, fin, dónde no hay fin, buscando, si con dezir Pausilipo se entiende quánto de honor le voy yo procurando? ${ }^{54}$

Sobre la falda suya que desciende hacia el Euboico mar, y al pueblo mira que aun de Parthenope el nombre defiende, Philón, armado de cayado y lira, estaba recostado baxo un pino, de su ganado que pacía a la mira, por donde Tagontín hacía camino -Tagontín el pastor más virtüoso que del Ibero en el Sebetho vino-, y dixo: «recostado hayas reposo calcídico pastor, quanto mi pecho está de reposar ya deseoso; ya haga la pastura tal provecho a tus ovejas qual la que mis ojos tomaron de mi bien a l'alma ha hecho».

Philón respuso: «y tú, libre de enojos te veas d'amor, y las tuyas agenas de ser de Licaón hechas despojos;

pon fin a tus palabras, que más llenas están de cortesía, que del Tago do tu naciste d'oro las arenas.

Siéntate, y si en loar plazer te hago cantando de tu Nice la belleça, solo quiero de ti la ayuda en pago".

Tagontín, sin respuesta y sin pereza, quitó del cuello la zampoña y manto 
Philón

$$
\text { Alto cielo pues diste }{ }^{55}
$$

a Nice sobre humana alma, tanto conforme a su figura en quien sola infundiste quanta dulceza mana y llueve sobre el mundo de tu altura, y tu, diosa Natura, que l'alma cobijaste con tan hermoso velo, o Phebo, honor del cielo, que con tus rayos siempre me inflamaste, espirad en mi iguales concectos a sus gracias inmortales.

Ilustre esplendor bivo de aquella efigie vera del sol de qu'en el sol nuestro es semblança, retracto al propio altivo de la beldad que impera, toda quanta belleza el mundo alcança, sol de virtu[d], esperanza de la luz de mis ojos, luz clara que escuresce la que más resplandesce, Nice, alivio especial de mis enojos, pues es vuestro el sugecto espirad en mi dél digno concecto.

Philón Quando el sol los calores en la canina estrella do cae l'amarillez al suelo abiva los huertos de sus flores, de su verdura bella los prados, con su fuentes d'agua priva, los arboles esquiva del nutrimento luego, con que sus fructos crescen, las miesses ya perescen todo lo seca el grande solar fuego, tal era antes mi vena que de humor fuesse d'Elicona llena.

55. celio] cielo. La lección transmitida por el impreso no tiene sentido. Se debe, probablemente, a una inversión de los caracteres en la caja de imprenta; «celio» se sustituye por «cielo», lección avalada tanto por el sentido general de la estancia como por los versos 289 y ss. en los que el poeta vuelve sobre el cielo y la natura que han dotado a Nice de sobrehumana hermosura. 
Tagontín Quando su lluvia envía

Jupiter en manera

de perlas, con que adorna Opis su falda,

bordado de alegría,

nos muestra primavera

su manto de cristal, y de esmeralda

ya texe su guirnalda

de flores muy hermosas

y de fructos Pomona,

ya Ceres se corona,

por pluvias biven ya todas las cosas

d'esteril, tal me ha hecho

la gracia que infundió Nice en mi pecho.

[Philón] Nice más rubios son vuestros cabellos ${ }^{56}$ que la madura espiga, y más delgados qu'el hilo qu'el gusano cría de aquellos que de los pueblos Seres son hilados, más luengos que los más crescidos vellos con que cobija Qenca sus ganados, llevan tras si los ojos do los lleva el aire en vista pelegrina y nueva.

Tagontín Nice, quien los cabellos vuestros mira ve los rayos del sol resplandecientes, ni es tan hermoso el oro que se tira más sotil en Arabia o de otras gentes, las almas por los ojos prende y tira de los cuerpos su vista y hace ausentes, colgadas d'ellos van por cada parte qu'el viento los revuelve y los desparte.

185 Philón que mi ganado enturbia o hoja encubre, muestra a quien se avecina claramente quanto en su fondo l'agua suya cubre, tal la hermosa y muy serena frente de Nice, el gran valor claro descubre a quien la mira, de que tiene lleno el más que el que lo es más templado seno.

Tagontín En la frente a Diana clara tanto no vido Endimión su alta ventura: ni Acteón su fortuna adversa, quanto en la frente que aquella hace escura del sol mío se paresce el zelo santo

56. En el impreso falta el nombre del pastor que recita estos versos, pero creemos que se trata de Philón, puesto que, en la serie de octavas en las que se canta la belleza de Nice, es sistemáticamente este el pastor que empieza la alabanza de la dama.

57. quieta] queta. 
del bien que l'alma enciende y la figura, ve en ella de su freno y su tormento todo atrevido y baxo pensamiento.

Philón

Quien ve d'hébano escuro guarnecidos dos espejos redondos, cristalinos, juntos y de una forma, y encendidos de los rayos del sol que están vezinos ve Nice vuestros dos ojos bellidos, de baxo de sus arcos hebeninos, pero en aquellos ve su propia forma y en los vuestros en piedra se transforma.

Tagontín

Con quanta embidia el sol os mira y vido, por ser muy más qu'el sol esclarecidos, luces suaves dulce d'amor nido, refugio de las mentes afligidas; en vos el proprio fuego está encendido del zelo que arde las celestes vidas, en vos se espeja l'alma, en vos se interna qual en presencia de la luz eterna.

Philón

Ayer, ayer vi yo, passando a caso por la casa d'Elisa, entre otras cosas, de blanca leche en un dorado vaso puestas dos frescas coloradas rosas, y dixe en el mirar, oh dulce caso: "estas son las mexillas tan hermosas de Nice, esto es su blanco y colorado, y sus cabellos son esto dorado».

Quien de l'alba al nascer nieve sincera d'un rosado esplendor colorar viere, o el alabastro donde reverbera rayo del sol qu'en roxo vidrio hiere, dirá, si las mexillas do se esmera la hermosura propia ver pudiere: "la nieve y alabastro descoloran l'alba, el sol, y esplendor que las coloran».

Philón

Es la nariz que de dos plumas pende de que orna el negro airón su mejor parte, qual lista de jazmines que desciende entre rosas, que tiene a cada parte poder la dulce voz bien se comprende, qu'entre el marfil y roxo coral parte de la boca de Nice, y los acentos firmar el sol y quietar los vientos.

Tagontín Es la nariz que de los arcos viene, de cuyos tiros son seños mis senos, 
de tanta perfición que en si no tiene do se pueda poner el más ni el menos; ni creo con más dulceça el canto suene de que están los celestes coros llenos, qu'el que entre perlas y rubines forma la boca de quien no es digna otra forma.

Philón Paréceme al mirar su blanco cuello

ver bien formado vaso cristalino con el cobertor d'oro, ni es tan bello el que alza el cisne en el rumor vecino; el pecho no lo he visto, mas sin vello diré qu'es parte del cuerpo divino qu'en todo es $\tan$ hermoso, y $\tan$ conforme quanto a su lor mi canto desconforme.

Tagontín

Formada en alabastro transparente con la corona d'oro la coluna de quien veremos coronar la frente, a mal grado y pesar de la fortuna, vi yo quando miré de la eccelente Nice el hermoso cuello, y si otra alguna cosa qu'el velo encubre decir osa lengua mortal será presuntuosa.

265 Philón

Tagontín

Hoy he visto ofrecer en el bel templo de Mergilina al bien de los humanos de blanca cera el casi al propio exemplo de aquellas lindas delicadas manos, y en su comparación, quando contemplo las uñas en los dedos soberanos, el ligustro sus hojas ve vencidas, y el nácar a sus perlas abatidas.

Las blancas manos, de las bellas bellas, por quien yo bivo, digo, por que muero, que quien las mira dexa l'alma entr'ellas, l'alma, que yo jamás cobrar no espero, ilustradas del sol vi yo tenellas Palas en el sepulcro de Sincero, que assí ilustra mi sol las sus gentiles cuyo esplendor es la lanza de Aquiles.

Philón

Las lágrimas que amor siempre derrama por las mexillas del ardiente amante, y todos los sospiros con que llama l'ausente amada el coraçón constante, y los muchos cuidados con que inflama Fortuna adversa la noble alma errante, contará, quien contar podrá los lores de la que a Tagontín mata d'amores. 


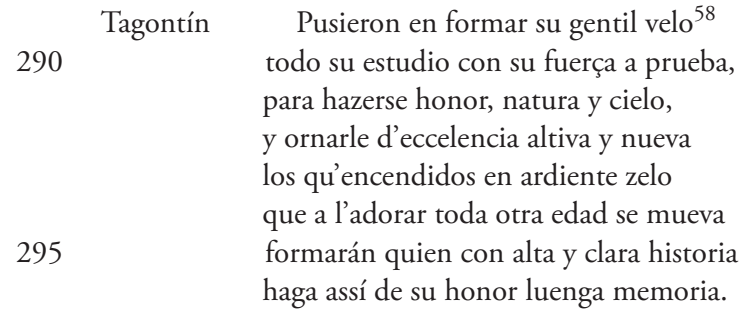

Esta más que otra alguna eccelsa y rara todo aparta de sí ciego sentido y la su pura mente orna y aclara

300

Tagontín Solo a la salamandra es nutrimiento de aquel bivo esplendor donde ha salido que por ella hazerse en todo clara todo mortal cuidado da al olvido y de sus pensamientos puesta encima contempla, alegre, l'alta causa prima.

Desde que fue en mi pecho descendida de su esplendor l'alta virtud divina, toda vil voluntad me fue encendida en un deseo gentil, que me encamina al bien eterno que, viendo esculpida mi alma en sí su forma pelegrina recibió calidad del bivo lumbre y volvió en alta toda vil costumbre. fuego, al camaleón el aire puro al arenque es el agua, al avariento sapo la tierra, do aun no está seguro; qual milagro será si un elemento simple da vida a un cuerpo, si te juro que yo de la memoria sola bivo d'haber visto una vez su esplendor bivo.

Philón Diana el arco amó más que otra cosa, Palas amó el telar do venció a Arańa, Ceres es de la hoz muy codiciosa quando ve ya madura su campaña, Nice, más que las tres, sabia y hermosa,

58. Acabado el elogio de las manos, con que se concluye la loa a la belleza de Nice, que empieza en el verso 171 con la celebración del esplendor de sus cabellos, a partir de este verso, en las 4 octavas seguidas, se interrumpe la alternancia del canto entre Philón y Tagontín y pasa a cantar únicamente Tagontín, si bien en el impreso el nombre solo aparezca junto a los versos 289 y 313. En efecto, en la octava anterior (vv. 281-288) Philón renuncia a cantar las cualidades intelectuales de Nice y sus efectos, dejando la ardua tarea al pastor que la bella dama «mata de amores». Tagontín es, evidentemente, el único autorizado a alabar a la mujer que, una vez que ha ocupado su corazón, ha permitido, gracias a sus divinas virtudes, que toda su «vil costumbre» se haya tornado en «alta». 
con las cartas d'Apolo se acompaña do quiera que de hoy más cartas se hallen, el arco, y el telar y la hoz callen.

Tagontín De tórtolas dio Tirsi a Phili un nido, 330 y Titire a Amarili dio un reclamo, Damón a Nisa un oso ya crecido, A Galatea Coridón un gamo, dar l'alma a Nice, don que ha así vencido, los de Tirsi, Damón, Coridón, amo, y al otro, como vence Nice a Phili a Nisa a Galathea y a Amarili.

Philón En tierra Pan de su Siringa ardía, y Glauco estando en mar de Galathea, Boreas amó en el aire a su Orthya y Marte en cielo amaba Citherea, más cada un amador d'estos seguía mil otras Nimphas, si Tagontín sea en tierra, en mar, en aire en cielo puesto de sola Nice amara siempre el gesto.

Junón a Samo, Palas a su Athenas Diana a Cynthia, y Venus Cipro honoran, gloria y honor que ya todos la adoran, por quien Parthenope dice: «si llenas de jatancia os mostráis por las que os moran a Cipro escurecer puede mi gloria, a Samo, a Cynthia, a Athenas por Victoria».

Ya no cantaban los pastores quando se vió Parthenope, docta serena, que con espanto había estado escuchando fuera del mar, sentada en el arena, muy dulcemente proseguir cantando la historia de eccelencia y d'honor llena y lo passado, por venir y ausente decía assí como quien lo ve presente. 


\section{Parthenope}

Hermosas nimphas que al celeste choro contino adornará vuestra presencia, y vos Eliconíades no feas, nereides que miráis tanta eccelencia por habitar las ondas do yo moro, dríades, amadríades, napeas, urdid vuestras choreas y venios a alegrar conmigo agora, ${ }^{59}$ del grande honor a qu'en todo otro cede, que a todas nos procede, del nuevo sol que entre nosotras mora, por quien Sebetho ameno irá y altivo, y el Tiber embidioso, qu'es dél privo, venid cantando a vencer toda historia con el esplendor bivo:

corred, pues es el fin, nimphas, Victoria.

Y vos, nimpha real, digna de imperio, mirad qual vuestra clara origen viene, de nobles paños y de virtud ornada, con gente qu'en el mundo par no tiene, cuya alteza ilustró nuestro hemisperio d'agudo hierro y de valor armada.

La frente coronada

d'oliva, palma, de laurel y d'oro, en carro triunphal del mil areos hostiles y tropheos, rodeada y seguida de un gran choro, d'encadenadas y diversas gentes a quien Sebetho y Tiber conoscientes que habíades vos de ser de Italia gloria decían, como presentes: corred pues es el fin, nimphas, Victoria.

Del cielo y de los Indos y Sabeos viene ya la gentil nimpha Natura, del oloroso y fértil oriente por buscar do hazer vuestra figura, tal que los más hermosos haga feos gestos, que hay en la edad nuestra presente, y trae para la frente lo blanco y lo sereno de Diana, del sol los rayos para los cabellos, para los ojos bellos la luz de cuya luz la del sol mana, los blancos lirios y bermejas rosas el ébano, alabastro y las preciosas 
piedras, qual no harán dulce memoria, que trae entre otras cosas.

Corred pues es el fin, Nimphas, Victoria.

Astrea, en cuyo gesto las centellas del fuego eterno, y en su azul vestido color rosado y oro fino luzen, viene con un celeste esclarecido manto de todas juntas las estrellas, que felices efectos nos producen $\mathrm{y}$ a entender nos conducen la beldad de la causa alta primera, ni es ya mortal quien d'ella se enamora por llegar a la hora en que vos ilustréis d'Opis la sphera haziendo fe del bien aquí del cielo, y cubriros nasciendo el sacro velo tan digno de poema alto y de historia quanto nos da consuelo.

Corred, pues es el fin, nimphas, Victoria.

Zephyro espira, de plazer caudillo, y huye a su venir el tiempo triste, ya el mundo se repara y se mejora, Opis, del verde manto ya se viste y de blanco, d'azul y d'amarillo para vos, Nice, se le borda Flora, Pomona ya colora su faz, y dora Ceres su cima, su fructo, y ramos ya la parra estiende por el olmo y desciende a que vos le pongáis la mano encima; mas las nimphas d'embidia se asen d'ellos $\mathrm{y}$ al retenerlos vuestros dedos bellos dice el árbol: «o, quanto habría de gloria si uno de los cabellos me queda qual tropheo de tal Victoria.»

Ya vienen las hermanas todas nueve, $\mathrm{y}$ os traen vasos d'humor del Elicona, con las cartas d'Apollo en que enseñaros, ya os dan de laurel verde la corona que vuestra bella frente ceñir debe, ya Pallas veo venir, docta, a mostraros sus artes y a envidiaros porque será de vos luego vencida, ya vienen las virtudes principales que las cosas mortales os hacen despreciar por la otra vida, ya de vos todo el cielo se enamora, ya todo el mundo os ama, ya os adora 
y os constituyen aras por memoria, del mundo vencedora corred, pues [es] el fin, nimphas, Victoria. ${ }^{60}$

460

Y para vos cargada de bien quanto Fortuna puede dar, Némesis guía una nave qu'el mar l'invidia todo, ella, qu'en su fiel governo fía no siente el cielo airado baxo un manto sereno armarse del solito modo, para mudar del todo su alegre estado, y darla al precipicio mientras que hiende el mar más sosegada, do, luego, arrebatada es d'un contrario viento, qu'el propicio vence, y seguir l'es fuerça otro camino, y llegar donde es presa d'un vecino, y saqueada, que de vera gloria en tierra no hay destino.

Corred, pues [es] el fin, nymphas, Victoria.

Enemiga Fortuna, si mi boca tus merescidos lores siempre ha dado a la inmortal memoria, es que contemplo tu tan ventoso y tan mudable estado: como quitas lo alto a quien le toca y lo das a quien no, como al exemplo de la bondad y al templo de virtud, por hacer que sea tan grande tu crueldad quanto su belda[d ]en tierra, ${ }^{61}$ moviste nueva guerra por dar a otro su estado a que lo mande; mas quien te vedará que lo enajenes en breve, ven tu Ninpha, no te penes: que quando, si merced sea transitoria, seguirás con tus bienes.

Corred pues es el fin, nimphas, Victoria.

Nice, tiempo verná, ya yo lo veo, que vos con más estado y más provecho los daños reparéis vuestros passados, y quedará del todo satisfecho de la digna de vos madre el deseo, y en gozo convertidos sus cuidados. Por vos serán atados los hilos del reinar que la Fortuna rompió a vuestros passados, y presentes claríssimos parientes,

60. En este verso y en el último de la estrofa sucesiva falta «es».

61. beldad] belda. 
y passaréis de allá vuestra Coluna

de las Ercúleas, donde será puesto:

«aquí fue el valor par del sin par gesto»;

y escrito en la Coluna por memoria

y blason trairéis esto:

encima de un Plus Ultra una Victoria.

Passara bien, con su sabroso canto, Parthenope adelante, a quien oían con atención las nimphas y pastores, sino que ya los montes escondían el sol de do caía el noturno manto estendiendo sus sombras ya mayores, que viendo de colores rosadas variarse y de fino oro las nubes, y huirse en todo el día cada nimpha su vía y la del mar tomó el Nereide choro, el qual junto a Megari un alarido alçó diciendo: «a Dios, de beldad nido, a Dios, más que otro alguno venturoso»; y Tagontín partido Philón llevó el ganado a su reposo. 
